\title{
Mitral annuloplasty ring design and selection: Complete semi-rigid is best
}

\section{Taweesak Chotivatanapong, MD}

Mitral annuloplasty with prosthetic ring is an integral part of mitral valve repair. To understand the importance of this procedure we need to explore in depth the mitral annulus, its dynamics, and its important role in the mitral valve complex. This will lead us to conceptualize regarding design and best possible choice of valve ring in mitral valve repair.

\section{MITRAL ANNULUS}

Mitral annulus is a component of mitral valve complex. The complex comprises the left atrium, annulus, leaflets, chords, papillary muscles, and left ventricle. Mitral annulus is an integral part of the fibrous skeleton of human heart. Posteriorly, it consists of a very thin band of connective tissue where the posterior leaflet is inserted. This area is weak and no connection to any rigid structure and thus annular dilatation often occurs in this part. In contrast, anterior mitral annulus is connected to more rigid structure of aorto-mitral curtain reinforced by 2 strong structures, anterolateral and postero-medial fibrous trigones. This renders anterior annulus stronger and less subjected to dilatation. Normal mitral annulus is grossly circular during diastole and elliptical in systole. Four anatomical structures are close to the mitral annulus and it needs to be mentioned to avoid injury during mitral surgery. They are, namely, circumflex artery between the base of left atrial appendage and the anterior commissure, coronary sinus closed posterior leaflet attachment but $5 \mathrm{~mm}$ superior to the annulus, the bundle of His near the posteromedial trigone and last, the noncoronary and left aortic cusps close to the anterolateral trigone. ${ }^{1}$ With this anatomical structure the mitral annulus acts as a framework for mitral valve complex and actively supports valve function through delicate and complex annular dynamics.

\section{THE DYNAMICS AND SADDLE SHAPE OF THE MITRAL ANNULUS}

In contrast to most beliefs, the mitral annulus is not a planar or static structure. Instead it is a dynamic and

From the Central Chest Institute of Thailand, Cardiothoracic Surgery, Nonthaburi, Thailand.

Received for publication Aug 10, 2021; revisions received Oct 15, 2021; accepted for publication Oct 15, 2021; available ahead of print Oct 22, 2021.

Address for reprints: Taweesak Chotivatanapong, MD, Central Chest Institute of

Thailand, Cardiothoracic Surgery, Nonthaburi 11000, Thailand (E-mail:

twchoti@gmail.com).

JTCVS Techniques 2021;10:55-7

2666-2507

Copyright (C) 2021 The Author(s). Published by Elsevier Inc. on behalf of The American Association for Thoracic Surgery. This is an open access article under the CC BY-NC-ND license (http://creativecommons.org/licenses/by-nc-nd/4.0/).

https://doi.org/10.1016/j.xjtc.2021.10.036

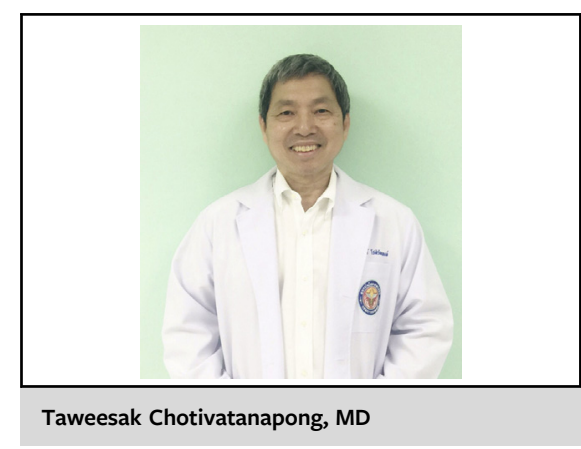

\begin{abstract}
CENTRAL MESSAGE
Mitral annuloplasty is integral in valve repair. Understanding of valve dynamics is crucial. Saddle shape reduces valve stress. Complete semi-rigid ring is best for valve repair.
\end{abstract}

3-dimensional one. It changes in size and shape throughout cardiac cycle. During diastole the annulus dilates to facilitate blood flow from the left atrium to the left ventricle. In systole, the base of the heart contracts and the aortomitral curtain displaces toward the center of the valve orifice. This results in reduction of mitral valve area close to $30 \%$, allowing anterior and posterior leaflets to close with good coaptation. The annular area varies from $5 \mathrm{~cm}^{2}$ to $11 \mathrm{~cm}^{2}$ (mean, $7 \mathrm{~cm}^{2}$ ). The mitral annulus has a 3-dimensional saddle-shape configuration. The 2 lowest points are located at the fibrous trigones and the 2 highest points are located at the midpoint of anterior and posterior annuli. The midpoint of the anterior annulus is higher. The saddle configuration is dynamic with its most marked at mid systole when the mitral valve is at its minimum valve area and more flattened during end diastole. ${ }^{2}$ It has been shown that the normal saddle shape of the mitral annulus correlates well with better distribution of stress to the mitral valve. ${ }^{3}$ Normal dynamics of the saddle-shape configuration during the cardiac cycle is thus paramount for good mitral valve function and to reduce stress, a favorable factor for good long-term durability of valve repair.

When the mitral annulus is affected by a pathological process, the results might vary depending on the causative 
disease. The pathological triad of etiology, lesion, and dysfunction advocated by Carpentier and colleagues ${ }^{1}$ is important. This separation facilitates understanding and plan of treatment because prognosis depends on etiology, repair strategy depends on dysfunction, and techniques depend on lesions. For example, the annulus might dilate posteriorly in degenerative valve or be grossly dilated in Barlow's disease, whereas it might become thickened, fibrotic, or calcified in rheumatic valve. This might deform the annulus and significantly disturb its dynamics. All of this will dictate the proper choice of valve ring on a case by case basis. The valve pathology as well as underlying heart disease also influences selection of type and size of valve ring regarding the prevention of post valve repair complications. For example, patients with excessive leaflet tissue with a small left ventricle, acute mitral aortic angle, or hypertrophic cardiomyopathy patients, special attention should address the potential problem of systolic anterior motion (SAM). Thorough understanding of the pathophysiology of SAM will mandate the choice of valve ring to avoid this dreadful complication. ${ }^{4}$

With the previously mentioned multiple factors, one can appreciate the challenge of best mitral annuloplasty ring selection for mitral valve repair. With varied causative diseases and different annular pathologies, the ideal valve ring to correct the different defects and at the same time to maintain normal integrity of mitral dynamic and shape is truly a nail-biting task.

\section{THE GOALS OF MITRAL VALVE RING}

To rationally select the best possible valve ring, certain pertinent qualities should be possessed by the chosen ring: (1) The ring should restore normal annular size on the basis of precise measurement for each individual patient. It should also attain the flexibility to allow the annuls to change in size and shape during cardiac cycle. This property is important for good left ventricular function. ${ }^{5}$ (2) The ring should be 3-dimensional and dynamic saddle shape. This will reduce valve stress, maximize leaflet coaptation, and optimize mitral dynamics., ${ }^{3,6,7}$ (3) The ring should remodel the annulus to achieve the systolic shape with the transverse diameter $(\mathrm{T})$ and anteroposterior diameter (A) ratio of 4:3. This will assure the maximal leaflet coaptation and prevent further deformity. ${ }^{1}$ (4) The ring should maximally support and reduce stress on the delicate valve repair procedures. This will secure durability and good long-term results. ${ }^{1,3,6}$

With these pertinent requirements, it makes complete semi-rigid mitral annuloplasty ring the best choice for mitral valve repair in most cases. Mitral annuloplasty with a partial band support the mitral annulus from trigone to trigone on the posterior aspect. In cases with complex repair procedures or very dilated annular pathology, the remodeling support can be less strong because of the lack of enforcement from all sides. However, for less complex valve repair, small annulus, or concern of risk of SAM, partial band annuloplasty is an attractive and viable option. A flexible annuloplasty ring offers a dynamic device and provides improvement of left ventricular function. ${ }^{5}$ However, when the pathological annular lesion is very severe with significant geometrical deformation, a flexible ring might not be strong enough to effectively remodel the annulus. A recent study on 3-D echocardiographic analysis of mitral annular dynamics showed evidence of abnormal annular dynamics of myxomatous mitral regurgitation with rapid annular dilatation in early systole. A flexible device is less effective to remodel and restore normal annular dynamics and anatomy. ${ }^{8}$ Current complete semi-rigid rings have a saddle shape, which connects to the flexible posterior part of the annulus. The valve ring is thus mobile and provides a dynamic saddle shape. The saddle configuration usually is more prominent in systole and less during diastole. It remodels the annulus to attain systolic shape with a T:A diameter ratio of 4:3, which will maximize coaptation and secure good long-term results. The anterior part is either flexible or with a prebuilt curve to conform with under the left ventricular outflow tract to improve good systolic flow to the aortic valve. With a complete ring design, it gives maximal support from ALL sides of annulus, ensuring minimal stress on the valve repair procedures to achieve better durability and long-term results of valve repair. ${ }^{1}$ With all of these mentioned properties, a complete semi-rigid mitral annuloplasty ring should be the best choice in mitral valve repair. Excellent mitral valve repair results with the use of a complete semi-rigid ring has been shown and clearly pointed out its role in mitral valve repair. ${ }^{9-13}$ For other causes with different valve pathologies and lesions, different types of valve ring with particular designs and characters have been used with good outcomes. ${ }^{14-18}$

To conclude, there is still no PERFECT mitral annuloplasty ring. But with current understanding and better design of mitral annuloplasty rings, complete semi-rigid mitral annuloplasty rings should be considered as the BEST choice for most patients with mitral valve repair.

\section{Conflict of Interest Statement}

The author reported no conflicts of interest.

The Journal policy requires editors and reviewers to disclose conflicts of interest and to decline handling or reviewing manuscripts for which they may have a conflict of interest. The editors and reviewers of this article have no conflicts of interest.

\section{References}

1. Carpentier A, Adams D, Filsoufi. Surgical anatomy and physiology. In: Carpentier's Reconstructive Valve Surgery. Philadelphia, PA: Saunders Elsevier; 2010 $27-41$.

2. Castillo JG, Solís J, González-Pinto A, Adams DH. Surgical echocardiography of the mitral valve [in Spanish]. Rev Esp Cardiol. 2011;64:1169-81. 
3. Padala M, Hutchison RA, Croft LR, Jimenez JH, Gorman RC, Gorman JH III, et al. Saddle shape of the mitral annulus reduces systolic strains on the P2 segment of the posterior mitral leaflet. Ann Thorac Surg. 2009;88:1499-504.

4. Mihaileanu S, Marino JP, Chauvaud S, Perier P, Forman J, Vissoat J, et al. Left ventricular outflow obstruction after mitral valve repair (Carpentier's technique). Proposed mechanisms of disease. Circulation. 1988;78:I78-84.

5. David TE, Komeda M, Pollick C, Burns RJ. Mitral valve annuloplasty: the effect of the type on left ventricular function. Ann Thorac Surg. 1989;47:524-7; discussion: 527-8.

6. Skov SN, Røpcke DM, Tjørnild MJ, Ilkjær C, Rasmussen J, Nygaard H, et al. The effect of different mitral annuloplasty rings on valve geometry and annular stress distribution. Interact Cardiovasc Thorac Surg. 2017;24:683-90.

7. Ryomoto M, Mitsuno M, Yamamura M, Tanaka H, Fukui S, Tsujiya N, et al. Is physiologic annular dynamics preserved after mitral valve repair with rigid or semirigid ring? Ann Thorac Surg. 2014;97:492-8.

8. Levack MM, Jassar AS, Shang EK, Vergnat M, Woo YJ, Acker MA, et al. Threedimensional echocardiographic analysis of mitral annular dynamics: implication for annuloplasty selection. Circulation. 2012;126(11 Suppl 1):S183-8.

9. Perier P, Hohenberger W, Lakew F, Batz G, Diegeler A. Rate of repair in minimally invasive mitral valve surgery. Ann Cardiothorac Surg. 2013;2:751-7.

10. Mohty D, Orszulak TA, Schaff HV, Avierinos JF, Tajik JA, Enriquez-Sarano M. Very long-term survival and durability of mitral valve repair for mitral valve prolapse. Circulation. 2001;104(12 Suppl 1):I1-7.

11. Gardner MA, Hossack KF, Smith IR. Long-term results following repair for degenerative mitral regurgitation - analysis of factors influencing durability. Heart Lung Circ. 2019;28:1852-65.
12. De Bonis M, Alfieri O, Dalrymple-Hay M, Del Forno B, Dulguerov F, Dreyfus G Mitral valve repair in degenerative mitral regurgitation: state of the art. Prog Cardiovasc Dis. 2017;60:386-93.

13. Coutinho GF, Antunes MJ. Mitral valve repair for degenerative mitral valve disease: surgical approach, patient selection and long-term outcomes. Heart. 2017; 103:1663-9.

14. David TE, Armstrong S, McCrindle BW, Manlhiot C. Late outcomes of mitral valve repair for mitral regurgitation due to degenerative disease. Circulation. 2013;127:1485-92.

15. Lange R, Guenther T, Kiefer B, Noebauer C, Goetz W, Busch R, et al. Mitral valve repair with the new semirigid partial Colvin-Galloway Future annuloplasty band. J Thorac Cardiovasc Surg. 2008;135:1087-93.E4.

16. Alferi $\mathrm{O}$, De Bonis M. Mitral valve repair for functional mitral regurgitation: is annuloplasty alone enough? Curr Opin Cardiol. 2010;25:114-8.

17. Chotivatanapong T, Lerdsomboon P, Sungkahapong V. Rheumatic mitral valve repair: experience of 221 cases from Central Chest Institute of Thailand. $J$ Med Assoc Thai. 2012;95(Suppl 8):S51-7.

18. Shimokawa T, Kasegawa H, Matsuyama S, Seki H, Manabe S, Fukui T, et al. Long-term outcome of mitral valve repair for infective endocarditis. Ann Thorac Surg. 2009;88:733-9; discussion: 739.

Key Words: mitral valve repair, mitral annuloplasty ring, prosthetic mitral valve ring, complete semi-rigid ring, mitral annulus, mitral dynamics, mitral complex 